\title{
Research on the management mode of Vocational School Physical Education Teaching Based on the whole media
}

\author{
Huaping Luo \\ Hunan chemical industry professional technology institute, foundational courses department, \\ Zhuzhou 412004, China \\ aluo@163.com
}

Keywords: Whole media, Vocational school physical education, Management mode.

\begin{abstract}
Based on the departments and processes system management of PE education, I choose the J2EE development platform and the Struts-MVC hierarchical structure design patterns is used. Generally the powerful exercise framework and good design patterns are used to develop the J2EE application, this can shorten the time of design as soon as possible. Struts is a MVC-based J2EE platform design framework, which reduces the workload on building the multilayer Web applications and also provides a recycled software framework. But the MVC design pattern has obvious advantage in multilayer Web applications on data processing, it is helpful for large-scale application software development. The studies in this thesis are based on the Struts framework system development technology. After discussing on J2EE study, further studies on MVC model are presented. Large amount of references are referred to. The demand of PE education is analyzed based on the characteristics of high school teaching management. According to a detailed analysis of requirements, design exercises have been done aiming at the common PE quality evaluation management system, $\mathrm{PE}$ education operating management system and the PE teaching resources management system. Software system is obtained based on the Struts framework model development, which is reliable on practical PE education management.
\end{abstract}

\section{Introduction}

The national Ministry of Education Sports and health department issued the "guidelines" national ordinary higher vocational higher vocational colleges sports curriculum teaching, the new guidelines in the "CPC Central Committee and the State Council on the basis of deepening issued by the education reform and promoting quality education decision" State Council and the "Regulations on school sports" is proposed, it is China's reform of higher vocational higher vocational colleges sports on the basis of. In recent years, higher vocational higher vocational colleges sports teaching reform in our country continuously, the breadth and depth of reform are in constant development, but from the 'Outline' to have a certain distance to reach the goal. [1]

With the popularizing of computer technology, it is applied widely in all industries in China and great achievements are obtained. As well as the computer technology is popularized in university Physical Education (PE). [2] Nowadays the number of student increases rapidly, also the complexity of PE management corresponding increases. The PE education has the following characteristics: large amount of information, strong ability on information processing, long time information preservation and so on. Therefore, reliable, efficient and stable computer information processing platform is in needed. [3] The physical education teaching management (PETM) is a process of planning, organizing, controlling and monitoring the physical education teaching in accordance with the law of PE. PE teaching plays an integral part in school's PE work and the quality of PETM is central to PETM, which is, therefore, an overall process management with an aim to increasingly improve the teaching quality. Present situation of Physical Education in higher vocational colleges and universities $(n=10)$ is shown in Table 1 . 
Table 1 Present situation of Physical Education in Higher vocational colleges and Universities ( $\mathrm{n}=10$ )

\begin{tabular}{|c|c|c|c|}
\hline Type & Time & Textbook & Outline \\
\hline 2 & 726 & 234 & 2882 \\
\hline 20 & 708090 & 632 & $\begin{array}{llll}20 & 80 & 80 & 20\end{array}$ \\
\hline
\end{tabular}

\section{Organization of the Text}

Section Headings. The thesis chooses Hubei Province, an underdeveloped province in the west of China, as a case study to explore and analyze the current situation of PE teaching and the work of PETM in universities and college in Hubei Province. The methods employed in the research are literature review, experts' interview, interview survey, questionnaire, case study method and statistical analysis. Survey of teaching mode is shown in Table 2.

Table 2 Survey of teaching mode

\begin{tabular}{cccc}
\hline Type & No. & $\%$ & $\mathrm{~N}$ \\
\hline Lub & 1 & 25.7 & 9 \\
Three type & 2 & 17.1 & 6 \\
Two section & 3 & 14.2 & 5 \\
Integrated type & 4 & 8.6 & 3
\end{tabular}

Organization of the paper. Physical education management is a basic way for the completion of PE teaching PE teaching is an important part in school's PE work. PETM, a kind of effective management of the PE teaching process and each teaching link, combined with PE's teaching objectives, characteristics and the law in light of theories and methods of tasks. Hence, it is required that PETM be characterized as specialization trait in itself with a view to the increasing development of the teaching quality as well as the implementation of the overall process management on the basis of grasping PE teaching mechanism, strengthening the information feedback of the permeable teaching management process, establishing a powerful teaching management system and measures and forming the characteristics of PETM approaches. Sport basic course content is shown in Table 3.

Table 3 Sport basic course content

\begin{tabular}{cl}
\hline School & \multicolumn{1}{c}{ Content } \\
\hline $\begin{array}{c}\text { Huazhong university of } \\
\text { science and technology } \\
\text { Wuhuan university }\end{array}$ & $\begin{array}{l}\text { Basketball, football, volleyball, badminton, table } \\
\text { tennis, tennis } \\
\text { Taiji boxing, Basketball, football, volleyball, } \\
\text { badminton, table tennis, tennis }\end{array}$ \\
$\begin{array}{c}\text { Wuhan University of Science } \\
\text { and Technology }\end{array}$ & $\begin{array}{c}\text { Aerobics, Basketball, football, volleyball, } \\
\text { badminton, table tennis, tennis, A martial art } \\
\text { Hubei University }\end{array}$ \\
& $\begin{array}{r}\text { Taekwondo, Basketball, football, volleyball, } \\
\text { badminton, table tennis, tennis }\end{array}$ \\
\hline
\end{tabular}

The work of PETM in some universities and higher vocational colleges in Hubei Province has such problems as the relatively low professional titles and the imbalance of educational background structure, the disconnection of teaching management between the department in charge of school's teaching and that undertaking PE teaching task, lack of system, science and practicality in the plan of teaching work, the incompletion and poor fulfillment of teaching management system. However, the study reveals that universities and higher vocational colleges having gone through and to go through the Education Ministry's evaluation for the undergraduate teaching work level not only have noticeable improvement in the areas mentioned above, but also develop their own PE teaching and management features and coordinated systems.

Higher school's PETM is still in the exploratory stage, in which many problems need to be studied. The PETM we have been advocating is supposed to center on 'humanism' scientific management on the basis of teaching, research and management, which involves the application of certain disciplines, such as, linguistics, sociology, psychology, physiology, philosophy and management. It is essential 
that, guided by the new pedagogical management concept, the talent development pattern be carried out from a perspective of the combination of knowledge, capability and quality with emphasis on humanistic teaching and respect for knowledge and meanwhile, integrating PE teaching management into internationalization, a brand-new teaching management pattern and humanistic environment be constituted so as to continuously innovate the teaching management mechanism, achieving the innovation of PETM in an all-round way.

In the meantime, in view of the problems with PETM of higher schools in Hubei Province, quite practical suggestions and strategies conforming to PETM of higher schools in Hubei Province are provided in order that methods adopted in PETM of higher schools in Hubei Province might be more modern, standards standardized, goals serialized, practice for further deepening the PE reform and improvement of higher schools in Hubei Province. Quantitative statistics of PE is shown in Table 4.

Table 4 Quantitative statistics

\begin{tabular}{ccccc}
\hline & $\begin{array}{l}\text { Wuhan } \\
\text { uneverdity }\end{array}$ & $\begin{array}{l}\text { Huazhong } \\
\text { university of } \\
\text { science and } \\
\text { technology }\end{array}$ & $\begin{array}{c}\text { Hubei } \\
\text { university }\end{array}$ & $\begin{array}{c}\text { Wuhan } \\
\text { university of } \\
\text { science and } \\
\text { technology }\end{array}$ \\
\hline $\begin{array}{c}\text { Basterball } \\
\text { hall }\end{array}$ & 4 & 6 & 4 & 9 \\
$\begin{array}{c}\text { Volleyball } \\
\text { hall }\end{array}$ & 7 & 2 & 1 & 5 \\
$\begin{array}{c}\text { Badminton } \\
\text { hall }\end{array}$ & 8 & 3 & 1 & 6 \\
$\begin{array}{c}\text { Table } \\
\text { tennis hall }\end{array}$ & 5 & 4 & 9 & 4 \\
\hline
\end{tabular}

\section{Analysis of Existing Problems}

Take Physical Education in Private Higher vocational colleges for example. This paper has studied 16 Private higher vocational colleges of Hubei Province, only those who have been officially authorized to issue diplomas by Ministry of Education. The study has adopted many approaches, such as literature, questionnaire, interview and mathematical statistics etc. The author has investigated the construction of PE teachers, Physical Education, the sports studying of students, [4-5] the structures of the stadium, the input of PE founds and the attitude of the leadership, and reached the following conclusions: PE teachers in private higher vocational colleges and universities of Hubei Province composed by full-time and part-time teachers. This structural model is one of the major feature of private higher vocational colleges and universities in Hubei Province, but the proportion of part-time teachers is too high, that has affected the stability of teachers; Teachers are relatively younger; The structures of titles and qualifications are irrational; The level of teachers' scientific research is low; Teachers have fewer training opportunities; Teachers' salaries are relatively low. PE teachers in private higher vocational colleges and universities of Hubei Province have a deep understanding of teaching objectives; Teaching content don't prominent occupational characteristics; Teaching methods are outdated; teaching evaluation has been more substantial reforms. Physical Education Curriculum in Private Higher vocational colleges and Universities of Hubei Province exist serious problem, it has a serious shortage of class, not in conformity with the provisions of the Ministry of Education. So far, no one private higher vocational college has its own textbooks. The students in Private Higher vocational colleges and Universities have strong sense of PE, the majority of students enjoy physical education lessons. Sports venues and equipment are difficult to meet the needs of PE teaching. A considerable portion of school leaders don't attach importance to PE. 8) Overall innovative efforts of Physical Education is not enough, the reform is not completed and haven't show its own characteristics. (Fig. 1) 


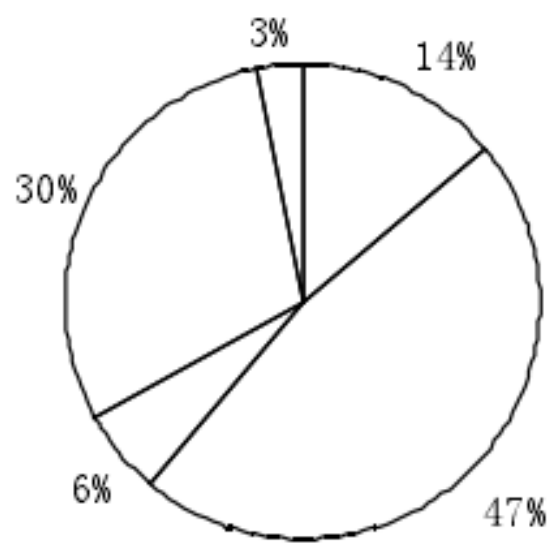

Fig. 1 PE exercise time

References are cited in the text just by square brackets. (If square brackets are not available, slashes may be used instead, e.g. /2/.) Two or more references at a time may be put in one set of brackets [3, 4]. The references are to be numbered in the order in which they are cited in the text and are to be listed at the end of the contribution under a heading References, see our example below.

\section{The Whole Media Using in PE}

The development and building of higher vocational college PE teaching management information system plays an important role for the improvement of the higher vocational college P. E teaching administration, and optimizes obviously the quality and efficiency of higher vocational college P.E teaching administration. Management information system for P. E teaching administration, which is in the research developed, is mainly consists of four First Sub-systems: P.E educational programs and plans, teaching resources, teaching operations, educational quality and evaluation, this system has realizes the wide share of $\mathrm{P}$. E. teaching information and optimizes impact fully the quality and efficiency of higher vocational college P.E teaching administration. The first sub-system, named P.E teaching programs and plans management system, mainly contains programs and plans made by the state, by the university and those by P. E. Department of University (details such as teaching syllabus, the general teaching plans of the Department, teaching plans made by the individual sports offices and even the specific teaching processes directed under each coaches). This sub-system has 3 second sub-systems for the management of P.E teaching programs and plans made by the state, by the university and those by P. E. Department of University (details such as teaching syllabus, the general teaching plans of the Department, teaching plans made by the individual sports offices and even the specific teaching processes directed under each coaches). (Fig. 2)

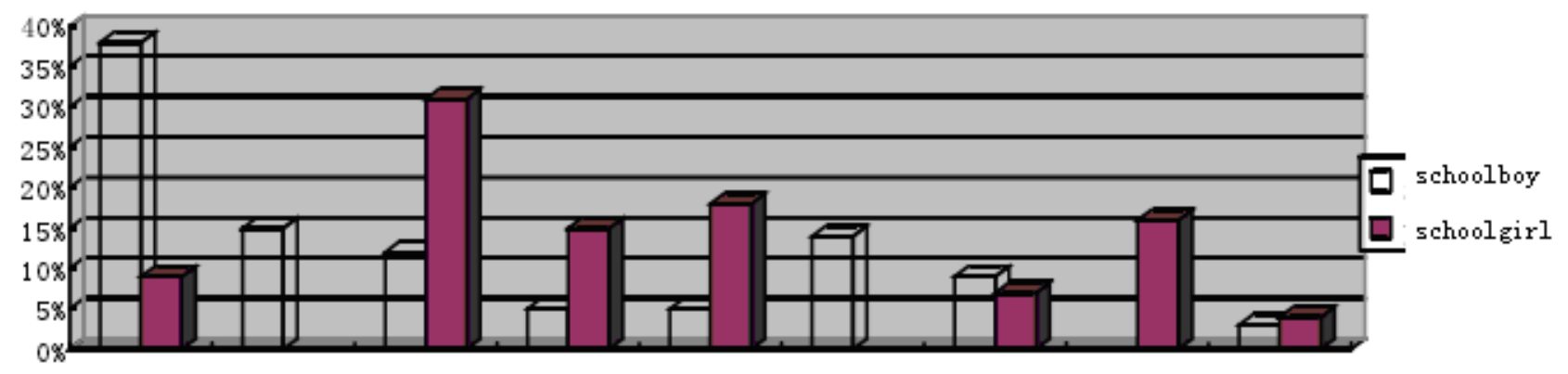

Fig. 2 student choice

The management information system for P.E teaching programs and plans actually can put into reality non-paper management and remote sending or browsing information. The another first sub-system, called sports resources management system, should cover the management of human resources, enough budgets, necessary facilities, fundamental constructions, researches for present and the future development. The sports HR management system is also an important sub-system, 
which contains the information of the staff of the Department and basic staff subsidy, automatically makes both easier and more correct; any changes, adjustment or remote reading can be done on the net. In the third first sub-system, namely teaching management operation, we emphasize the management of routine sports teaching activities, the organization of large-scale group sports activities, sports teams management, management of teaching loads and teaching materials and documents. In this system, 2 sub-systems for student's selection of sports and student's sports records management also have been successfully realized. The teaching management operation system, in which the specific sub-systems: sports selection system and sports record system can also realize automatically the student's remote selection of sports activities and the sports records statistics. The fourth sub-system is called educational quality and evaluation, which is comprised of teaching quality monitoring, analysis and evaluation. The PE teaching quality monitoring sub-system has been developed and realizes the evolution of PE teaching with network. (Fig. 3)

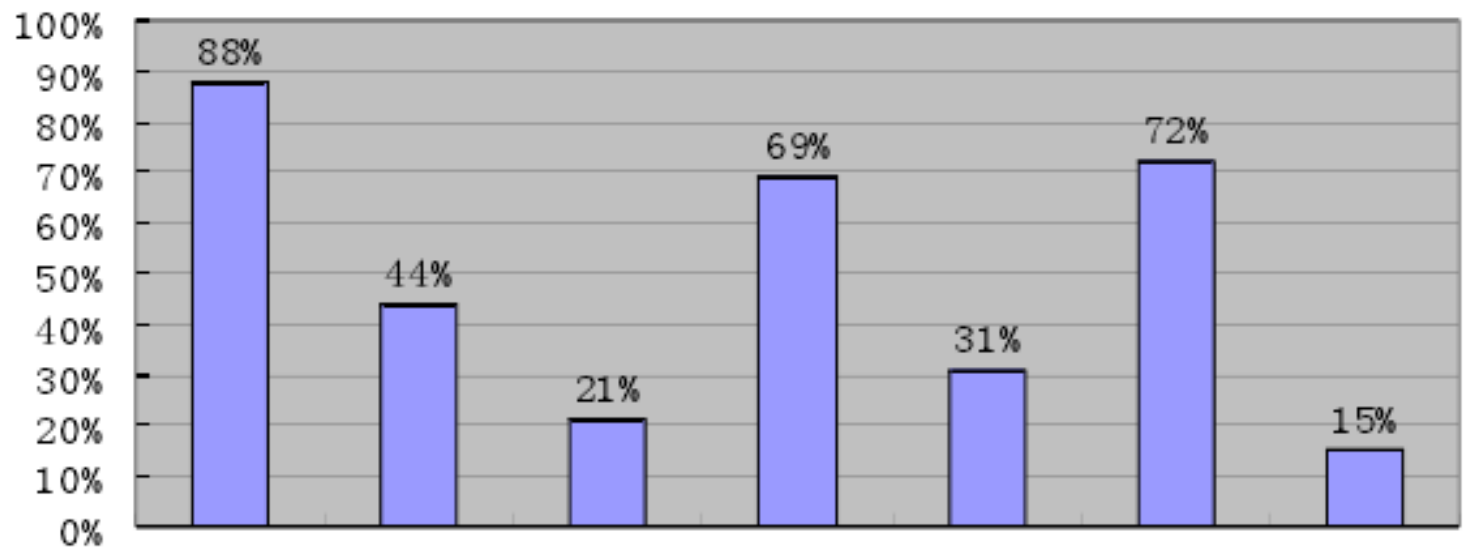

Fig. 3 Participation in physical activity survey

\section{Conclusions}

The dissertation covers an overall analysis and study on the development and application of management information system for higher vocational college P. E. teaching administration with the help of the following research methods: wide documents selections, questionnaires, mathematical statistics, systemization and deduction, testing, etc. It focuses on the programs and plans for P.E education, teaching operation management, educational quality and evaluation, as well as developing a suitable and practical management information system for sports education and management, hoping to develop a scientific, up-dated and normalized system so as to improve the quality and efficiency of higher vocational college P. E. teaching administration.

\section{References}

[1] X.Zhang, P.Chen, M.Zhao. Data expression method in enterprise application using J2EE architecture. WSEAS Transactions on Communications, 2008, 7(6): 541-550.

[2] J.Guo, H.Yue, Behzadl A performance validation tool for J2EE applications. Proceedings of the International Symposium and Workshop on Engineering of Computer Based Systems, 2006: 387-396.

[3] L.Hui. SQL/SDA, a query language for supporting spatial data analysis and its Web-based implementation, IEEE Transactions on Knowledge and Data Engineering. 2012: 23-45.

[4] McClure, R. A. Kruger. SQL DOM:compile time checking of dynamic SQL statements,software Engineering, 2005: 20-21.

[5] Muralidhar Krishnaprasad Liu, Z. H. Anand Manikutty Warner, J. W. Vikas Arora. Towards an industrial strength SQL/XML infrastructure, Data Engineering, ICDE, 2014: 25-26. 